\title{
Evolution of the Inclusion Population During the Processing of Al-killed Steel
}

Marcos A. Mata-Rodríguez ${ }^{1)}$, Martín Herrera-Trejo ${ }^{1) *}$, Rodolfo Sánchez-Martínez, Manuel Castro-Román ${ }^{1)}$, Fabián Castro-Uresti ${ }^{2}$, Arturo I. Martínez-Enriquez ${ }^{1)}$

1) Centro de Investigación y de Estudios Avanzados, CINVESTAV Saltillo, Av. Industria Metalúrgica No. 1062, Parque Industrial Saltillo-Ramos Arizpe, Ramos Arizpe, Coah., 25900 México. marcos.mata@cinvestav.edu.mx (M.M.-R.); martin.herrera@ cinvestav.edu.mx (M.H.-T.); rodolfo.sanchez@cinvestav.edu.mx (R.S.-M.); manuel.castro@ cinvestav.edu.mx (MC.-R.); arturo.martinez@cinvestav.edu.mx (A.M.-E.).

2) Ternium México, San Nicolás de los Garza, N.L., 66450 México; fcastro@ternium.com.mx.

*Corresponding author: martin.herrera@ cinvestav.edu.mx, phone: +528444389643

\begin{abstract}
The increasing demand for higher inclusion cleanliness levels motivates the control over the formation and evolution of inclusions in the steel production process. In this work, the evolution of the chemical composition and size distribution of inclusions throughout a slab production process of Al-killed steel, including ladle furnace (LF) treatment and continuous casting (CC), was followed. The initial solid $\mathrm{Al}_{2} \mathrm{O}_{3}$ and $\mathrm{Al}_{2} \mathrm{O}_{3}-\mathrm{MgO}$ inclusions were modified to liquid $\mathrm{Al}_{2} \mathrm{O}_{3}-\mathrm{CaO}-\mathrm{MgO}$ inclusions during $\mathrm{LF}$ treatment. The evolution of the size distributions during LF treatment was associated with the growth and removal of inclusions, as new inclusions were not created after the deoxidation process, according to a population density function (PDF) analysis. Additionally, the size distributions tended to be similar as the LF treatment progressed regardless of their initial features, whereas they differed during CC. Analysis of the upper tails of the distributions through generalized extreme values theory showed that inclusion distributions shifted from larger to smaller sizes as the process progressed. There were great changes in the distributions of large inclusions throughout the LF treatment and between the end of the LF treatment and the start of the CC process. Additionally, distributions of large inclusions differed at the end of the LF treatment, whereas such differences decreased as CC progressed.
\end{abstract}

Keywords: Inclusion, size distribution, population distribution function, extreme value theory. 
$14 / 05 / 2021$

\section{Introduction}

The inevitable presence of inclusions in steel products has led steelmakers to pay particular interest to the control of inclusions by focusing on decreasing the number and size and controlling the morphology and chemical composition [1,2]. Successful control of the inclusion population requires knowledge of its formation and evolution throughout the steelmaking process.

Recent papers analyzed the origin and characterization of populations of inclusions $[3,4]$. In $\mathrm{Al}$ deoxidized steels, the deoxidation product solid $\mathrm{Al}_{2} \mathrm{O}_{3}$ can have different morphologies depending on the degree of saturation of dissolved aluminum and oxygen [4]. The $\mathrm{Al}_{2} \mathrm{O}_{3}$ inclusions can be modified via inclusion-steel reactions. Consequently, inclusion modification depends on the chemical evolution of the liquid steel during treatment in a ladle furnace (LF), which in turn depends on the addition of alloying elements, reactions of the steel with slag and refractory, and the homogenization of liquid steel [4-9]. After $\mathrm{Al}_{2} \mathrm{O}_{3}$ inclusions form, they can subsequently transform into $\mathrm{Al}_{2} \mathrm{O}_{3}-\mathrm{MgO}$ inclusions $[9,10]$; however, inclusions of the type $\mathrm{Al}_{2} \mathrm{O}_{3}-\mathrm{MgO}-\mathrm{CaO}$ have been observed during ladle furnace treatment [6,7]. At the end of LF treatment, the composition of the inclusions is modified by $\mathrm{Ca}$ addition to form liquid inclusions of the $\mathrm{Al}_{2} \mathrm{O}_{3}-\mathrm{CaO}$ type [11]. The $\mathrm{Ca}$ treatment efficiency seems to depend on the type of inclusions present before the modification treatment, i.e., $\mathrm{Al}_{2} \mathrm{O}_{3}$ or $\mathrm{Al}_{2} \mathrm{O}_{3}-\mathrm{MgO}$ inclusions, [5,10,12-14] and the homogenization of dissolved $\mathrm{Ca}$ in the liquid bath [15]. In addition, a decrease in temperature occurs progressively in the operations following the LF treatment, i.e., transfer of the ladle to the continuous casting (CC) station and the $\mathrm{CC}$ process, and the thermodynamic conditions of the liquid steel-inclusion interactions change and consequently the chemistry of the inclusions can be modified. On the other hand, a desirable inclusion population implies low numbers and small sizes of inclusions, which is reached through the efficient removal of inclusions during LF treatment and subsequent operations.

The removal of inclusions during LF treatment depends on numerous factors, such as the chemical compositions and sizes of the inclusions, flow pattern of the liquid steel, and slag properties [5]. Once the LF treatment is finished, the transport of the ladle to the continuous casting station and the $\mathrm{CC}$ operation itself provide an additional opportunity for flotation and removal of inclusions [7]. 
$14 / 05 / 2021$

On the other hand, the inclusion size distribution is commonly represented by a histogram and a plot of the frequency of inclusions as a function of the inclusion size, assuming a normal distribution [16,17]. These representations provide limited information on the inclusion population. Instead, the formalism proposed by Higgins that introduces the concept of the population density function (PDF) can be used [18]; the PDF is unique for a given inclusion population and provides information on the formation and evolution of inclusions [17]. On the other hand, the use of the generalized extreme values (GEV) theory based on Murakami et al.'s pioneering work [19] has been used to describe the large particle size tail of the distribution. For example, Ekengren and Bergström [20] described the upper tail of inclusion size distributions in industrial-scale samples. More recently, Castro et al. [21] and García et al. [22] used GEV theory to describe the evolution of the upper tail of the inclusion size distribution throughout the steelmaking process.

Thus, the improvement of inclusion cleanliness implies knowledge about the evolution of the inclusion population throughout the steelmaking process. The present work presents the characterization of inclusion populations in samples obtained in 4 heats conducted at an industrial scale facility. A sampling procedure was used throughout the steelmaking process, including the LF treatment and CC. The chemical composition of inclusions was estimated to follow its evolution throughout the steelmaking process. Furthermore, the inclusion populations were characterized in terms of their size distributions. The PDF concept was used to analyze and explain the evolution of the size distributions, whereas GEV theory was used to describe the evolution of the upper tail of the size distributions.

\section{Description of the steelmaking process}

This study involved the production of an Al-killed steel slab by the electric arc furnace (EAF)-LF-CC route (Figure 1). 1. A mix of directly reduced iron and scrap is the raw material used to produce primary steel in the EAF. After chemical composition and temperature adjustment, the steel is tapped into a 150-ton ladle. During that operation, a deoxidizer, ferroalloys, and slag-forming agents are added to the stream of liquid steel. After the tapping operation, the ladle is transported to an LF station, and the steel treatment starts with the adjustment of the chemical composition of the slag and the homogenization of the 
composition and temperature of the steel by controlled argon stirring. Then, the reactions of interest are promoted and controlled to reach the specified concentrations of alloying and residual elements. The liquid steel is then subjected to a calcium inclusion modification treatment through the injection of $\mathrm{CaFeAl}$ wire under controlled stirring. The LF treatment ends with a period of gentle stirring to promote inclusion flotation from the steel, and then the ladle is transferred to the CC station where a flotation period precedes the CC operation to promote the removal of inclusions. Additionally, removal of inclusions occurs during the CC operation.

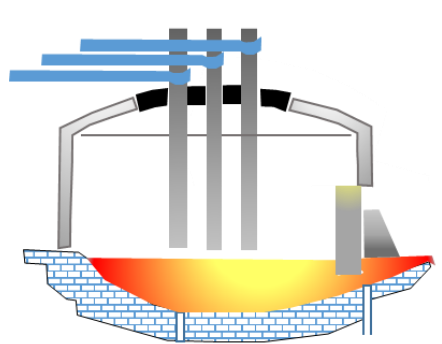

EAF

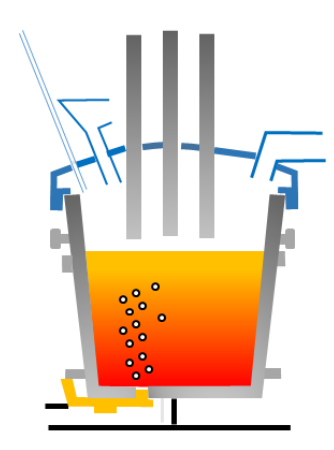

LF

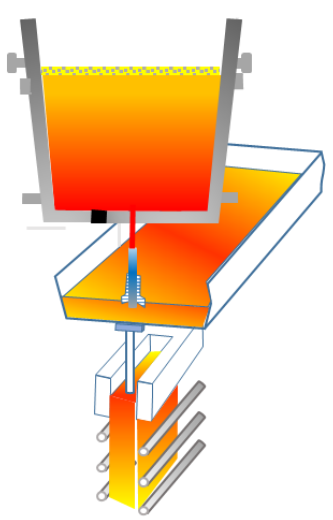

CC

Figure 1. Process route of the thin slab production plant.

\section{Experimental procedure}

\subsection{Plant trials}

Four successive plant production heats of a low-carbon aluminum-killed steel were studied. The heats corresponded to the first four heats of a 24-heat casting sequence. The chemical composition of the batches of steel at the end of the LF treatment is presented in Table 1; carbon and sulfur contents were determined by the Leco technique, and other elements were determined by optical emission spectrometry. 
Table 1. The chemical composition (wt-\%) of steels at the end of the LF treatment.

\begin{tabular}{cccccccc}
\hline Heat & $\mathbf{C}$ & $\mathbf{M n}$ & $\mathbf{P}$ & $\mathbf{S}$ & $\mathbf{S i}$ & $\mathbf{A l}$ & $\mathbf{C a}$ \\
\hline $\mathbf{A}$ & 0.044 & 0.185 & 0.003 & 0.003 & 0.019 & 0.040 & 0.003 \\
$\mathbf{B}$ & 0.053 & 0.174 & 0.002 & 0.003 & 0.013 & 0.042 & 0.003 \\
$\mathbf{C}$ & 0.043 & 0.183 & 0.003 & 0.003 & 0.019 & 0.036 & 0.002 \\
$\mathbf{D}$ & 0.046 & 0.178 & 0.003 & 0.002 & 0.025 & 0.038 & 0.002 \\
\hline
\end{tabular}

As the first stage of the experimental procedure, liquid steel was sampled during the LF treatment and at the CC mold using a cap-protected lollipop-type sampler. The samples were labeled according to their site and time of collection, as indicated in Table 2.

Table 2. Time of collection and nomenclature.

\begin{tabular}{lc}
\hline \multicolumn{1}{c}{ Time of collection } & Nomenclature \\
\hline Arrival to LF, after initial deoxidation & LF-I \\
Intermediate LF treatment, before Ca treatment $(\mathrm{CaFeAl})$ & LF-II \\
End LF treatment, after Ca treatment $(\mathrm{CaFeAl})$ & LF-III \\
Continuous casting mold, after pouring 40 tons of liquid steel & CC-I \\
Continuous casting mold, after pouring 120 tons of liquid steel & CC-II \\
\hline
\end{tabular}

The liquid steel samples were obtained in duplicate at each step: one sample was used for chemical analysis, and the other was used for characterization of the inclusion population. Furthermore, slag samples were drawn along with the samples of liquid steel in LF. X-ray fluorescence spectrometry was used to measure the elemental composition of slag and estimate its chemical composition and conversion to typical oxides, Table 3.

\subsection{Inclusion size distribution and statistical analysis}

Selected surfaces of the specimens were metallographically prepared to estimate the amount and size of inclusions. Each lollipop-type sample was axially sectioned, and one of the fresh surfaces was progressively dry ground using 80-, 220-, 300-, 500-, 800-, and 1000grit SiC papers and polished with 3- and 1- $\mu \mathrm{m}$ diamond pastes. Measurements were conducted with a Nikon Eclipse MA200 optical light microscope at 200x magnification, and image analysis was performed on 200 fields. The total analyzed surface area was $93.4 \mathrm{~mm}^{2}$ 
$14 / 05 / 2021$

per sample. For image acquisition, the specifications in the ASTM E-2283 standard were respected [23].

Table 3. Chemical composition of LF slags.

\begin{tabular}{|c|c|c|c|c|c|c|c|}
\hline \multirow[b]{2}{*}{ Heat } & \multirow[b]{2}{*}{ Sample } & \multicolumn{5}{|c|}{ Content (wt-\%) } & \multirow{2}{*}{$\begin{array}{c}\% \mathrm{FeO} \\
+ \\
\% \stackrel{\mathrm{MnO}}{ }\end{array}$} \\
\hline & & $\overline{\mathrm{Al}_{2} \mathrm{O}_{3}}$ & $\mathrm{CaO}$ & MgO & $\overline{\mathrm{SiO}_{2}}$ & $\mathrm{MnO}$ & \\
\hline \multirow[b]{3}{*}{ A } & LF-I & 37.66 & 49.08 & 8.42 & 2.61 & 0.10 & 0.64 \\
\hline & LF-II & - & - & - & - & - & - \\
\hline & LF-III & 38.05 & 49.31 & 8.48 & 2.75 & 0.10 & 0.71 \\
\hline \multirow[b]{3}{*}{ B } & LF-I & 31.8 & 55.02 & 7.98 & 3.13 & 0.26 & 1.38 \\
\hline & LF-II & 33.36 & 55.05 & 7.45 & 2.41 & 0.29 & 1.29 \\
\hline & LF-III & 32.29 & 54.51 & 7.36 & 2.46 & 0.31 & 2.17 \\
\hline \multirow[b]{3}{*}{ C } & LF-I & 30.7 & 51.71 & 9.56 & 4.2 & 0.45 & 2.86 \\
\hline & LF-II & 35.72 & 50.46 & 8.45 & 2.87 & 0.78 & 1.27 \\
\hline & LF-III & 36.56 & 51.33 & 8.61 & 2.94 & 0.14 & 0.62 \\
\hline \multirow[b]{3}{*}{ D } & LF-I & 31.28 & 50.26 & 8.87 & 4.11 & 0.34 & 1.5 \\
\hline & LF-II & - & - & - & - & - & - \\
\hline & LF-III & 35.33 & 51.01 & 8.22 & 2.68 & 0.06 & 0.33 \\
\hline
\end{tabular}

The analysis of the inclusion size distributions was conducted using the concept of PDF proposed by Higgins [18]. The PDF is expressed by the following:

$$
P D F=\frac{n_{v}\left(L_{X Y}\right)}{\left(L_{Y}-L_{X}\right)}
$$

where $n_{v}\left(L_{X Y}\right)$ is the frequency of inclusions in each size bin (particle number per bin volume), $\left(L_{Y}-L_{X}\right)$ the bin width is expressed in units of length ${ }^{-4}$. This treatment assumes that a log-normal distribution can be used to fit the experimental data [18,24]. Additionally, a statistical analysis based on the statistical GEV theory was conducted to characterize the upper tail of the inclusion populations [16]. A detailed statistical background has been presented in previous papers [21,22], so only the necessary details specific to this paper are included here. In general, the GEV distribution was fitted to the experimental dataset of inclusion sizes, and the scale, shape, and location parameters were estimated. If the $\mathrm{k}$ parameter (shape parameter) is greater than zero, then the probability distribution function is expressed by: 
$14 / 05 / 2021$

$$
\mathrm{f}(\mathrm{x})=\frac{1}{\sigma} \exp \left(-(1+\mathrm{kz})^{-1 / \mathrm{k}}\right)(1+\mathrm{kz})^{-1-1 / \mathrm{k}}
$$

and the $\mathrm{CDF}$ (cumulative distribution function) is given by the following equation:

$$
\mathrm{F}(\mathrm{x})=\exp \left(-(1+\mathrm{kz})^{-1 / \mathrm{k}}\right)
$$

where $\sigma$ is the scale parameter, $\mathrm{z}$ is the reduced variable $(\mathrm{x}-\mu) / \sigma$, and $\mu$ is the location parameter.

To analyze the reliability of the resulting GEV distributions, the Anderson-Darling test was used to evaluate the goodness of fit of the GEV distribution to the experimental data. Thus, the resulting A-D statistic values, $\mathrm{A}^{2}$, expressed by

$$
\mathrm{A}_{\mathrm{n}}{ }^{2}=-\mathrm{n}-\sum_{\mathrm{i}=1}^{\mathrm{n}} \frac{2 \mathrm{i}-1}{\mathrm{n}} \ln \left(\mathrm{F}\left(\mathrm{x}_{\mathrm{i}}\right)\right)+\ln \left(1-\mathrm{F}\left(\mathrm{x}_{\mathrm{n}+1-\mathrm{i}}\right)\right)
$$

were compared, for a given confidence interval, to a given critical value estimated by the Monte Carlo method. In the $A_{n}{ }^{2}$ expression, $F\left(x_{i}\right)$ is the CDF of the GEV distribution, $n$ is the total number of observed inclusions, and $\mathrm{x}_{\mathrm{i}}$ is the $\mathrm{i}$-th measurement of inclusion size. If the $\mathrm{k}$ value is greater than zero, then the upper tail of the distribution does not tend to a finite value, and accordingly, a survival function $\mathrm{S}(\mathrm{x})$ is used instead as a cleanliness parameter. $\mathrm{S}(\mathrm{x})$, the complement of the CDF expressed by $\mathrm{S}(\mathrm{x})=1-\mathrm{CDF}$, represents the probability of having inclusions larger than a given size.

\subsection{Chemical analysis}

The chemical compositions of the inclusions were estimated using energy dispersive spectroscopy. Approximately 10 inclusions per sample were selected for analysis under a Phillips XL30 ESEM scanning electron microscope equipped with an EDAX Pegasus analyzer. The inclusions were classified as simple or complex; those that exhibited only one phase were labeled "simple", those that contained two phases were "complex": In complex inclusions the major phase was identified as the "matrix", and other phase was identified as "secondary".

\section{Results and discussion}

4.1. Evolution of the chemical composition of inclusions 
$14 / 05 / 2021$

The evolution of the chemical composition of inclusions throughout the sequence of steel samples is shown in Figure 2. Simple and complex inclusions were observed in all stages. Regarding the LF treatment (LF-I to LF-III samples), it was observed that the LF-I samples contained mostly simple pure $\mathrm{Al}_{2} \mathrm{O}_{3}$ inclusions, a lesser amount of rich $\mathrm{Al}_{2} \mathrm{O}_{3}-\mathrm{MgO}$ inclusions with $\mathrm{MgO}$ contents less than 10\%, and few complex inclusions with both matrix and secondary phase rich in $\mathrm{Al}_{2} \mathrm{O}_{3}$ and variable contents of $\mathrm{CaO}$ and $\mathrm{MgO}$. Later, for the LFII samples, the $\mathrm{Al}_{2} \mathrm{O}_{3}$ content decreased in both the simple inclusions and the matrix of complex inclusions, while $\mathrm{CaO}$ was detected in most of the inclusions. The ratio of simple to complex inclusions also decreased. The secondary phase of the complex inclusions presented variable contents of $\mathrm{Al}_{2} \mathrm{O}_{3}, \mathrm{MgO}$ and $\mathrm{CaO}$. At the end of the Ca treatment, LF-III samples, a dispersion in the contents of the different oxides was observed in the simple inclusions and the matrix and secondary phases of complex inclusions. This dispersion was associated with the presence of $\mathrm{CaO}$ in the inclusions. Additionally, it is worth noting that $\mathrm{CaS}$ was found in both simple and complex inclusions.

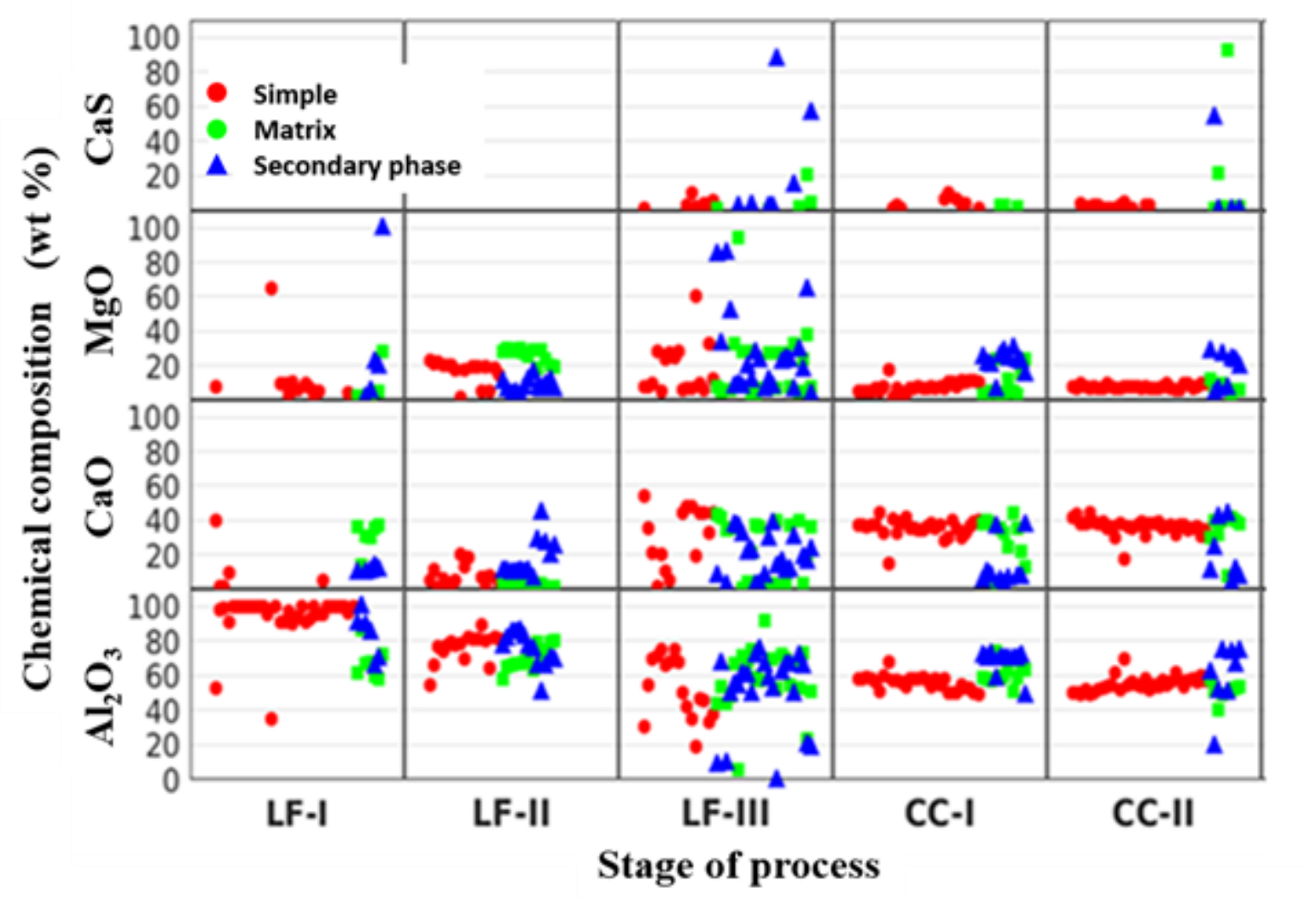

Figure 2. Chemical composition of inclusions throughout the steel production process. 
In the $\mathrm{CC}$, the composition of the simple and complex inclusions tended to be homogeneous in the $\mathrm{CC}$-I and CC-II samples. The simple inclusions had an $\mathrm{Al}_{2} \mathrm{O}_{3} / \mathrm{CaO}$ ratio of approximately 1.25 and $\mathrm{MgO}$ contents of less than $10 \%$. The chemical composition of both the matrix and secondary phase in the complex inclusions was variable and like that the simple inclusions. It is noteworthy that $\mathrm{CaS}$ was not found in secondary phases in complex inclusions in CC-I samples, whereas it was observed in CC-II samples.

\subsection{Path of inclusion modification}

To illustrate the modification path of inclusions through the processing of liquid steel,

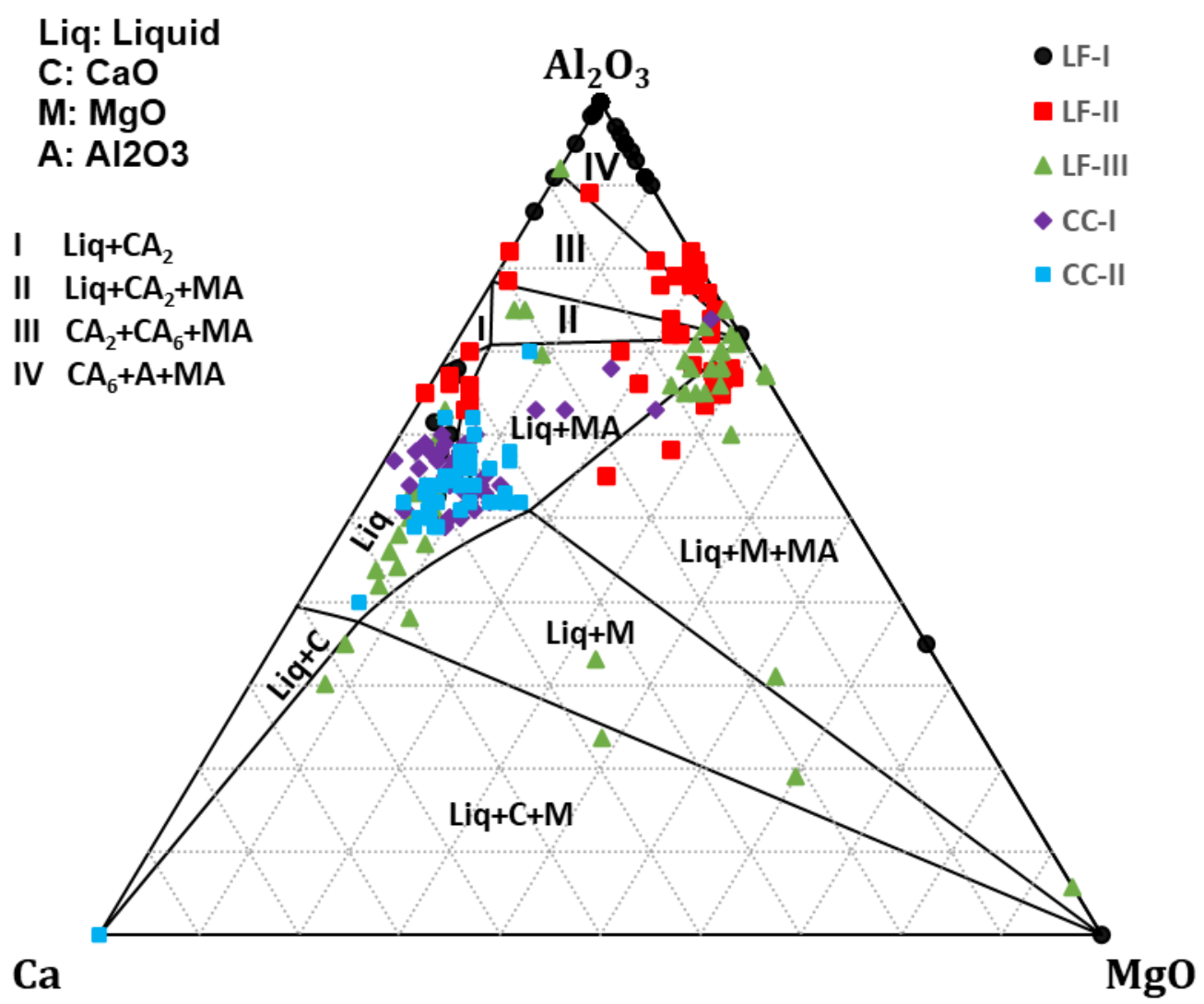

the contents of $\mathrm{Al}_{2} \mathrm{O}_{3}, \mathrm{CaO}$, and $\mathrm{MgO}$ in the analyzed inclusions were normalized and plotted on the $\mathrm{Al}_{2} \mathrm{O}_{3}-\mathrm{CaO}-\mathrm{MgO}$ ternary diagram at $1873 \mathrm{~K}$. This diagram was calculated using Thermocalc software [25] and the Slag2 database (Figure 3).

Figure 3. Evolution of the chemical composition of inclusions throughout the production process on the $\mathrm{Al}_{2} \mathrm{O}_{3}-\mathrm{MgO}-\mathrm{CaO}$ diagram at $1873 \mathrm{~K}$. 
$14 / 05 / 2021$

Most of the initial inclusions in the LF-I samples corresponded to solid pure $\mathrm{Al}_{2} \mathrm{O}_{3}$ and solid $\mathrm{Al}_{2} \mathrm{O}_{3}-\mathrm{MgO}$ inclusions near the $\mathrm{Al}_{2} \mathrm{O}_{3}$ corner. As the treatment of liquid steel in $\mathrm{LF}$ progressed, the inclusions shifted to higher $\mathrm{MgO}$ contents, and some were found in liquid regions because of their enrichment with $\mathrm{MgO}$ and $\mathrm{CaO}$. At the end of the $\mathrm{LF}$ treatment, despite the dispersion of data for the LF-III samples, most of the inclusions tended to be in the fully liquid region. Regarding the CC-I and CC-II samples, the chemical composition of almost all of the inclusions was in the fully liquid region, and the data dispersion was less than for the LF-III samples.

The observed initial solid $\mathrm{Al}_{2} \mathrm{O}_{3}$ inclusions were considered a product of the deoxidation reaction with aluminum [4]. The morphology of $\mathrm{Al}_{2} \mathrm{O}_{3}$ inclusions (Figure 4.a) indicates that they formed under typical deoxidation process conditions. i.e. high saturation regions of both dissolved oxygen and aluminum. Regarding the solid $\mathrm{Al}_{2} \mathrm{O}_{3}-\mathrm{MgO}$ inclusions found in that stage, it was thought that they originated from the reaction of $\mathrm{Al}_{2} \mathrm{O}_{3}$ inclusions with dissolved $\mathrm{Mg}$ from the aluminum deoxidizer and ferroalloys added during the tapping operation from the EAF to the LF. The interaction of $\mathrm{Al}_{2} \mathrm{O}_{3}$ inclusions with the slag was rejected as a $\mathrm{Mg}$ source because the slag had a relatively high oxidation state at that stage (average value of $\% \mathrm{FeO}+\% \mathrm{MnO}=1.5$ ), and there was not observed difference in chemical composition between the slag and the inclusions at that time.

The increased $\mathrm{MgO}$ content (approximately 20\%) in inclusions observed before the Ca addition, i.e., in the LF-II samples, was higher than that of the slag (approximately 10\%). $\mathrm{MgO}$ from the $\mathrm{MgO}$ ladle lining was considered as the most viable source of dissolved $\mathrm{Mg}$ in the liquid steel [6] that reacts with pre-existing $\mathrm{Al}_{2} \mathrm{O}_{3}$ and $\mathrm{Al}_{2} \mathrm{O}_{3}-\mathrm{MgO}$ inclusions. At that stage, some inclusions were modified by $\mathrm{Ca}$ to form solid and partly-liquid inclusions. The location of partly-liquid inclusions in the diagram of Figure 3 suggests that these inclusions resulted from the modification of $\mathrm{Al}_{2} \mathrm{O}_{3}-\mathrm{MgO}$ inclusions with high $\mathrm{MgO}$ contents. Liquid phase formation has been reported to occur in $\mathrm{Al}_{2} \mathrm{O}_{3}-\mathrm{MgO}$ inclusions, even at low $\mathrm{Ca}$ contents $[26,27]$. It was thought that $\mathrm{Ca}$ comes from the dissociation of $\mathrm{CaO}$ present in the slag and is promoted by the reduction conditions of the slag (average value of $\% \mathrm{FeO}+\% \mathrm{MnO}=0.6)$. $\mathrm{Ca}$ dissolved into the steel through steel-slag interactions, and its interaction with inclusions was promoted by the stirring of liquid steel. A typical inclusion 
at this stage is shown in Figure 4.b, where the matrix (gray phase) was composed of $\mathrm{Al}_{2} \mathrm{O}_{3}$ and $\mathrm{CaO}$ and the secondary phase (dark phase) consisted of $\mathrm{Al}_{2} \mathrm{O}_{3}-\mathrm{MgO}$.

(4.a)
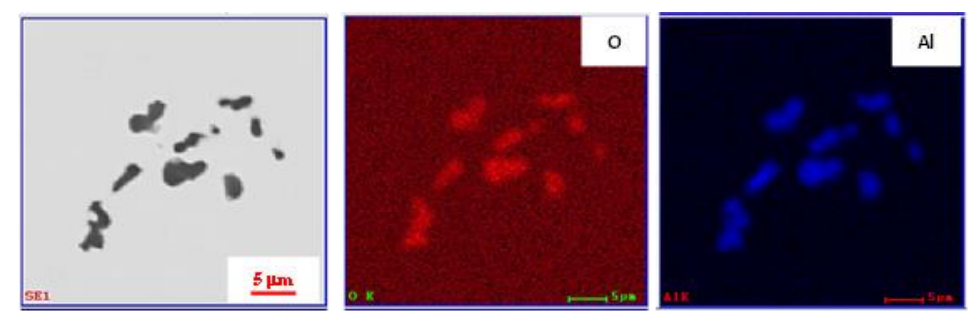

(4.b)
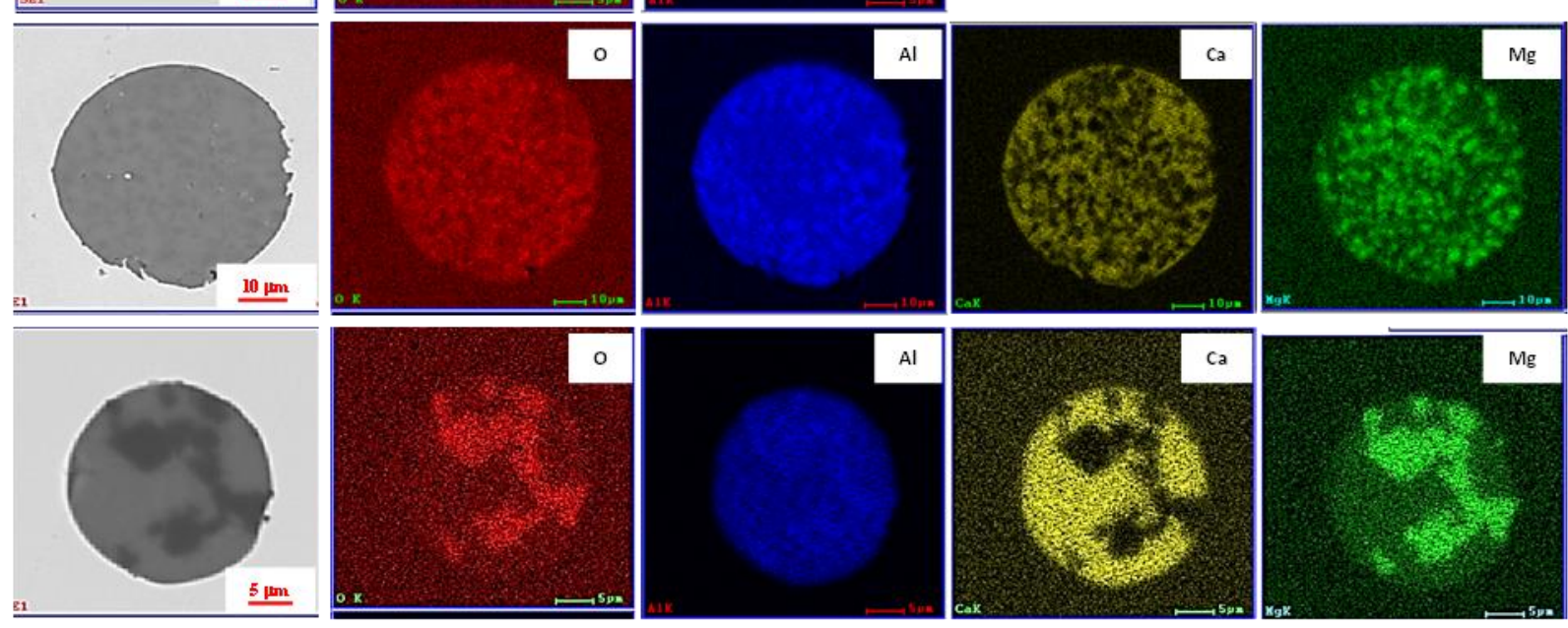

(4.d)
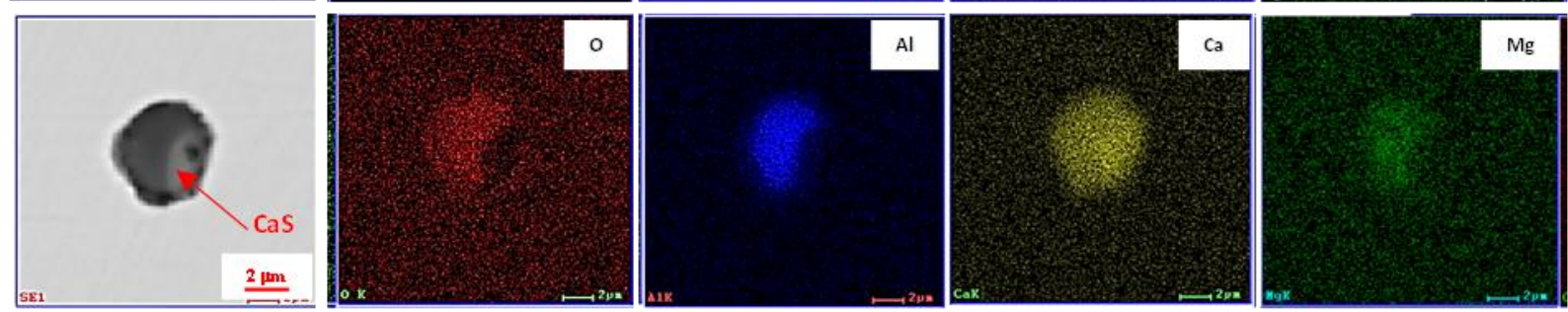

(4.e)
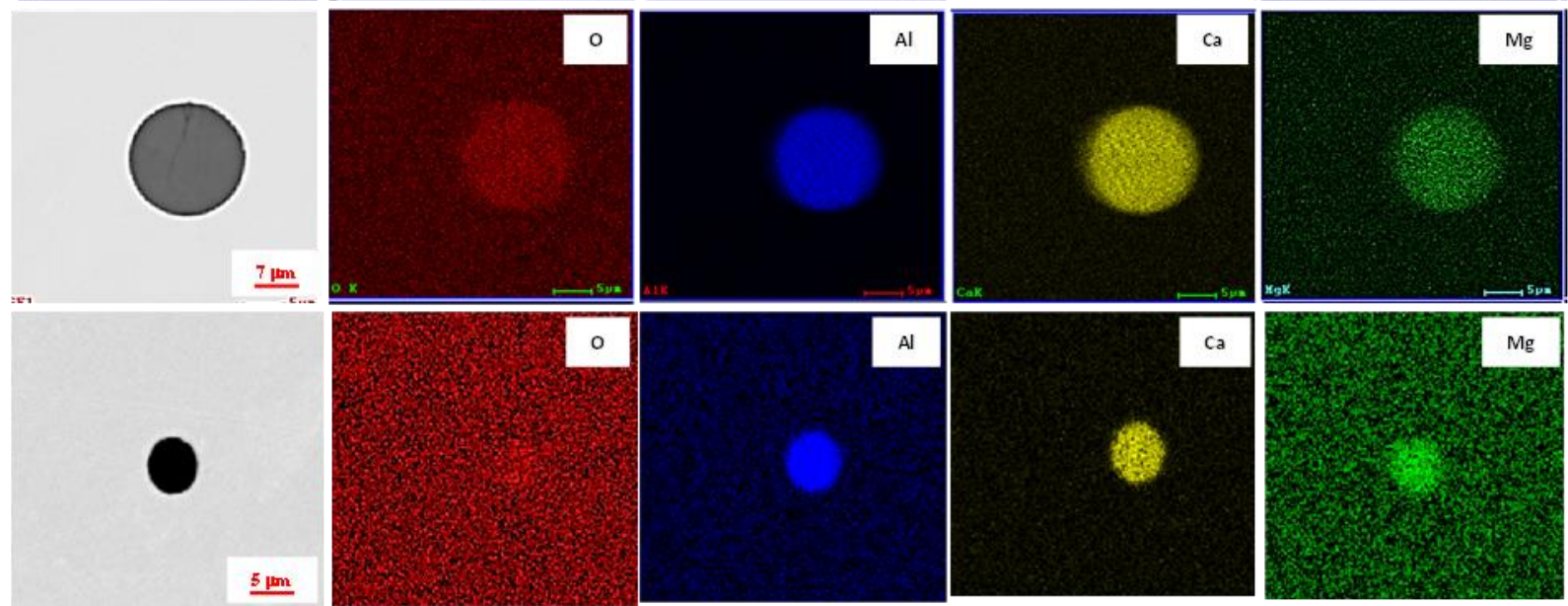

(4.f)

$\underline{5 \mu \mathrm{m}}$

Figure 4. Typical non-metallic inclusions at different sampling stages: (a) LF-I,

(b) LF-II, (c) and (d) LF-III, (e) CC-I and (f) CC-II. 
$14 / 05 / 2021$

Regarding the inclusions after Ca addition (LF-III samples), partially and fully liquid inclusions were found, (Figure 3). The heterogeneity of dissolved $\mathrm{Ca}$ after $\mathrm{Ca}$ addition promotes local zones with different driving forces for the modification of inclusions by $\mathrm{Ca}$. Thus, localized zones poor in dissolved $\mathrm{Ca}$ and the kinetics of inclusion modification itself delayed the modification process, leading to partial-liquid inclusions (Figure 4.c). As the dissolved $\mathrm{Ca}$ distribution became homogeneous, the kinetics of inclusion modification could play a determinant role, producing gradual inclusion modification. Therefore, it was expected that after a period of controlled gentle stirring and a period of inclusion flotation, the partlyliquid inclusions would be fully liquid. This was supported by the fact that most of the inclusions found in the CC-I samples were fully liquid, and there was little variation in their chemical compositions (Figure 3). Furthermore, in the complex inclusions in the LF-III samples, CaS was detected in secondary phases (Figure 4.d). It is assumed that the $\mathrm{Al}_{2} \mathrm{O}_{3}$ and $\mathrm{Al}_{2} \mathrm{O}_{3}-\mathrm{MgO}$ inclusions reacted with the dissolved $\mathrm{Ca}$ through the partial reduction of $\mathrm{MgO}$, followed by the partial reduction of $\mathrm{Al}_{2} \mathrm{O}_{3}$ and then the formation of $\mathrm{CaS}$. The presence of $\mathrm{CaS}$ in Ca-modified inclusions supports the modification mechanism of $\mathrm{Al}_{2} \mathrm{O}_{3}$ and $\mathrm{Al}_{2} \mathrm{O}_{3}$ $\mathrm{MgO}$ inclusions proposed by Verma et al. [28], consisting of the transient formation of CaS from dissolved $\mathrm{Ca}$ and $\mathrm{S}$ and the subsequent reaction of $\mathrm{CaS}$ with $\mathrm{Al}_{2} \mathrm{O}_{3}$. The transient character of the $\mathrm{CaS}$ is deduced from Figure 2, in which $\mathrm{CaS}$ was observed in secondary phases in LF-III samples but not in CC-I samples.

The observed inclusions in $\mathrm{CC}$ samples were fully liquid $\mathrm{Al}_{2} \mathrm{O}_{3}-\mathrm{CaO}-\mathrm{MgO}$ (Figure 4.e and Figure 4.f), where homogeneous distributions of $\mathrm{Al}_{2} \mathrm{O}_{3}, \mathrm{CaO}$ and $\mathrm{MgO}$ were observed. Some inclusions in CC-II samples showed a secondary phase composed of low levels of CaS (Figure 2). This was associated with the decrease in sulfur solubility due to the decrease in temperature associated with an increased residence time of the steel in the ladle [29].

\subsection{Distribution size}

Figure 5 shows the variation in the inclusion frequency (inclusions $/ \mathrm{mm}^{2}$ ) and area fraction for all heats. Both indicators decreased as the process advanced through the LF 
$14 / 05 / 2021$

stages, and from the LF-III samples to the CC samples, although the variation was less important, without a clear general trend.

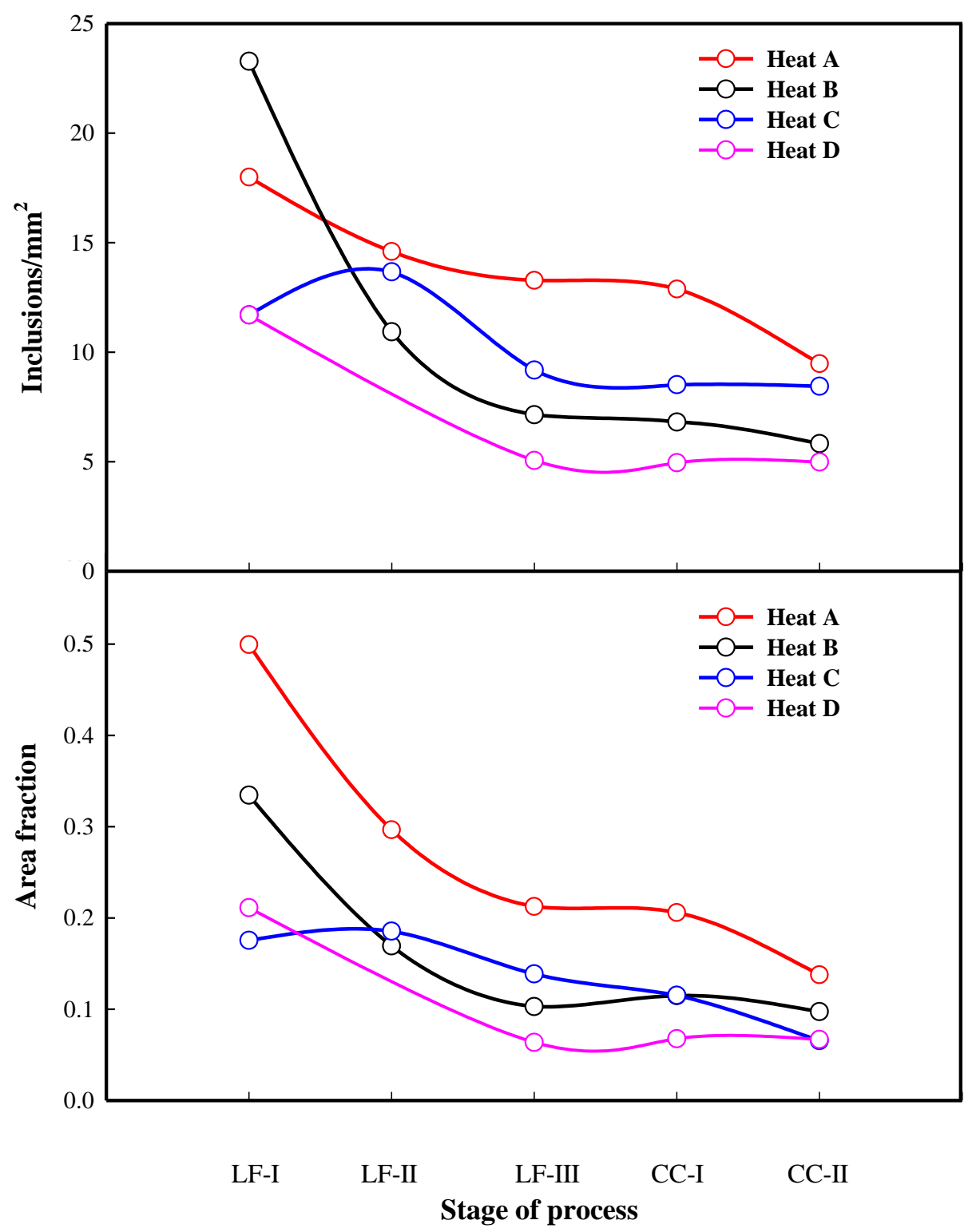

Figure 5. Evolution of inclusions $/ \mathrm{mm}^{2}$ and area fraction of inclusions.

To illustrate the evolution of the inclusion population throughout the steelmaking process, Figure 6 shows the evolution of the probability density function for Heat C, assuming a normal distribution. It was observed that the upper tail of the distributions shifted towards smaller sizes with the advance of the process, and that the means of the distributions 
were similar and located at approximately $4.5 \mu \mathrm{m}$. In addition, there was variation among the LF distributions and between the LF and CC-I distributions, whereas the CC distributions were very similar, and only the distribution for the CC-I sample was plotted. Similar behavior was observed in the rest of heats.

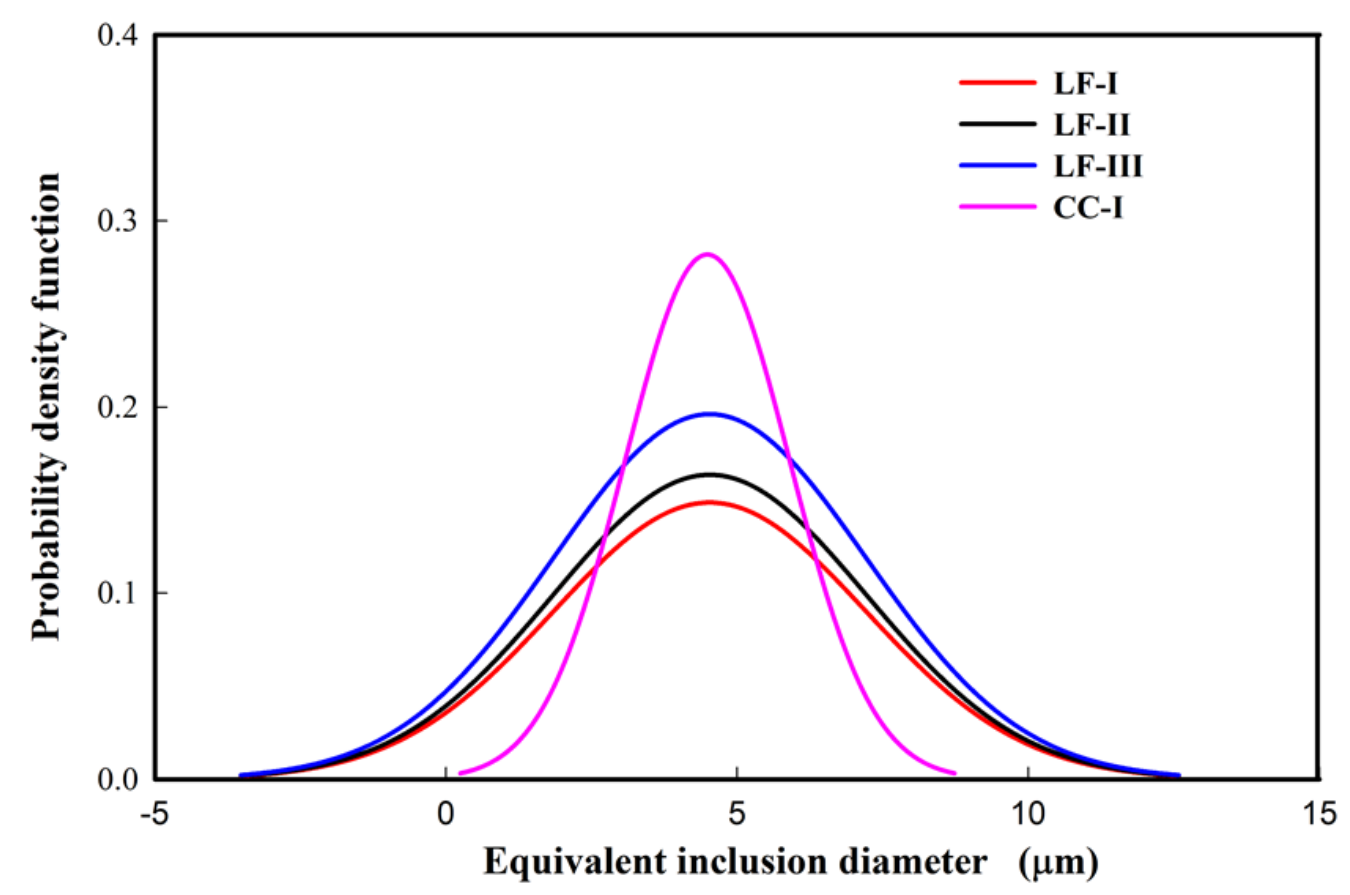

Figure 6. Evolution of the probability density function for Heat C.

To go deeper in the analysis of the evolution of the inclusion populations throughout the process, PDFs were calculated using Equation (1) based on the Higgins formalism [21]. To estimate the frequency of inclusions per unit volume, the $2 \mathrm{D}$ inclusion population information obtained by image analysis was transformed to 3D data via a procedure based on the Saltikov method [30,31]. The logarithmic representation of PDFs calculated for each sampling stage in LF treatment, LF samples, and all 4 heats is shown in Figure 7. Figure 7.a shows the PDFs corresponding to the LF-I samples, whereas those for LF-II and LF-III are shown in Figure 7.b. In general, the PDFs showed linear power law behavior [24]. The reference lines included in Figure 7 were estimated by considering the averages of data for inclusion sizes smaller than $9 \mu \mathrm{m}$, where the fitting to the linear behavior was remarkable. The linear behavior indicated that there was no formation of new inclusions during the LF 
$14 / 05 / 2021$

treatment, e.g., inclusions formed from reoxidation, and the observed evolution was associated with the growth and removal of inclusions [32,33].

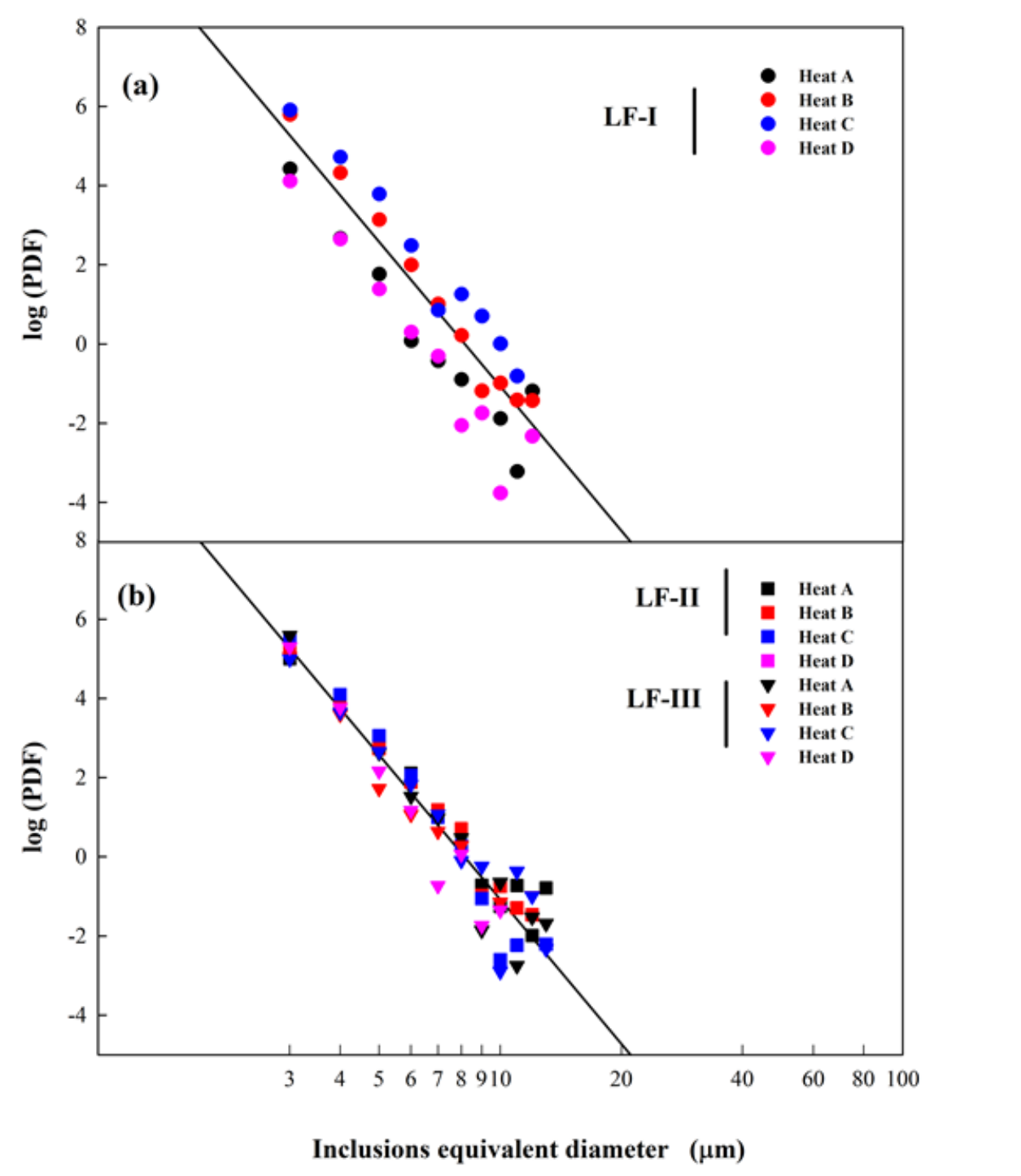

Figure 7. Log-log plots of PDFs versus inclusion equivalent diameter for LF.

The data for the LF-I samples (Figure 7.a) were farther from the reference line than the LF-II and LF-III data (Figure 7.b). This was associated with the intense transient deoxidation process that delayed the approach to dynamic inclusion-steel equilibrium at the beginning of LF treatment. For the LF-II samples, it was thought that equilibrium was 
$14 / 05 / 2021$

reached. Furthermore, the Ca addition seemed to not modify the inclusion population because similar behavior was exhibited by samples from LF-II and LF-III; however, instead, it is believed that the changes associated with the growth and/or removal of inclusions during the interval between the Ca addition, the LF-II samples, and the LF-III samples were not significant enough to be detected by the measurement procedure used in this study. The observed power law behavior and the similarity of the reference line slope values were considered characteristic of the applied LF treatment and reflect its reproducibility. It is worth noting that Van Ende et al. [17] observed power law behavior in PDFs obtained after the deoxidation of a low $\mathrm{C}$ steel produced in two plants. That behavior was characterized by a similar value of the slope of the reference lines. The value of the slope was attributed to the same deoxidation practice in both plants and associated with the dynamic equilibration of $\mathrm{Al}_{2} \mathrm{O}_{3}$ inclusions. On the other hand, the loss of linearity observed in the LF-II and LF-III samples, Figure 7.b, for inclusion sizes greater than $9 \mu \mathrm{m}$ was attributed to transient $\mathrm{Ca}$ inclusion modification process associated with the heterogeneity of dissolved $\mathrm{Ca}$ in the liquid steel, kinetics that delay the $\mathrm{Ca}$ inclusion modification and the decrease in the frequency of inclusions beyond that size.

The logarithmic representation of PDFs for CC samples is shown in Figure 8. In general, linear behavior with scattered data with respect to the reference line was observed. By considering the similarity of the PDFs of the LF-III samples, it was thought that the main source of the scattering was the dynamic inclusion removal behavior that depended on the residence time of inclusions in the steel. After $\mathrm{Ca}$ addition, inclusions tended to float out to the steel-slag interphase because of their buoyancy and the gentle stirring of the steel. Additionally, the collision of liquid inclusions during the flotation process promoted the growth and removal of inclusions, as larger inclusions float out more easily than smaller inclusions. Both removal mechanisms operated by buoyancy during the transfer of the ladle to the CC caster, the flotation period and the CC itself. Thus, inclusions had different residence times depending on their localization in the steel, the transfer time of the steel from the LF station to the CC caster, the flotation period and the progressive casting into the $\mathrm{CC}$ mold. However, despite the understanding of the mechanisms of inclusion formation, interactions among inclusions and inclusion removal, the stochastic nature of the LF process makes it difficult to obtain similar inclusion populations in plants for every single heat. 
Regarding the reference line, there were slight differences with respect to those of the LF samples. The slope shifted slightly to larger inclusion sizes and log (PDF) values, but the steepness of the slope was practically the same. These slight differences were attributed to the scattering of the data. It is worth noting that the CC-II samples of Heat A were less close to the reference line, which suggested that there was a deviation from the "standard" casting process. It is worth noting that the analysis in this paper applied strictly to inclusions smaller than $9 \mu \mathrm{m}$, which were used to obtain the reference lines. For larger inclusions, the data scattering restricted the analysis and suggested a deviation from the described behavior.

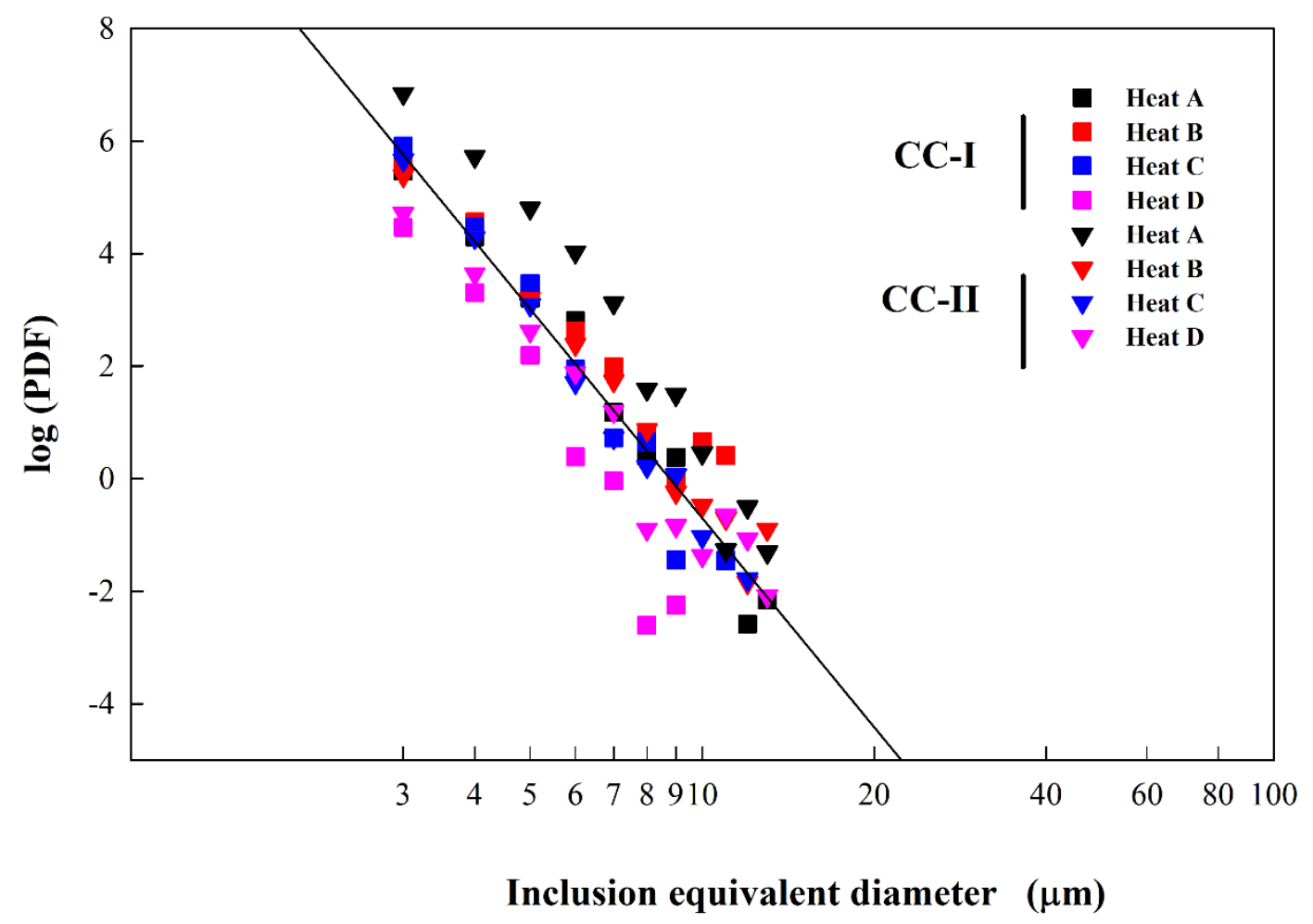

Figure 8. Log-log plot of PDFs versus inclusion equivalent diameter for CC samples.

\subsection{Analyses of the upper tail of size distributions}

For each sample, the measured size distributions were fitted to the GEV distribution, and the goodness of fit was estimated. Table 4 shows the GEV distribution parameters, $\mathrm{k}, \mu$ and $\sigma$, and the A-D statistics and critical values, $\mathrm{A}^{2}$, and CV obtained by tests of the goodness of fit. It was observed that practically all the tests, except one gave a good fit to the GEV 
$14 / 05 / 2021$

distribution, as the calculated A-D statistics were smaller than the critical value estimated by the Monte Carlo method.

Table 4. GEV distribution parameters and Anderson-Darling statistic values.

\begin{tabular}{|c|c|c|c|c|c|c|}
\hline \multirow{2}{*}{ Heat } & \multirow{2}{*}{ Sample } & \multicolumn{3}{|c|}{ Parameters GEV distribution } & \multicolumn{2}{|c|}{$\begin{array}{c}\text { Anderson-Darling } \\
\text { test }\end{array}$} \\
\hline & & $\mathbf{k}$ & $\bar{\sigma}$ & $\bar{\mu}$ & $\overline{A_{n}^{2}}$ & $\mathbf{C V}$ \\
\hline \multirow{5}{*}{ A } & LF-I & 0.83 & 31.30 & 34.55 & 0.28 & 2.71 \\
\hline & LF-II & 0.66 & 18.00 & 23.95 & 0.33 & 2.71 \\
\hline & LF-III & 0.83 & 10.66 & 16.65 & 0.64 & 2.39 \\
\hline & CC-I & 0.22 & 11.23 & 21.67 & 0.40 & 2.44 \\
\hline & CC-II & 0.03 & 6.77 & 16.11 & 0.42 & 2.45 \\
\hline \multirow{5}{*}{ B } & LF-I & 0.46 & 12.56 & 22.12 & 0.95 & 2.59 \\
\hline & LF-II & 0.47 & 10.31 & 16.52 & 1.42 & 2.46 \\
\hline & LF-III & 0.43 & 7.61 & 13.17 & 0.57 & 2.45 \\
\hline & CC-I & 0.03 & 7.45 & 17.12 & 0.82 & 2.52 \\
\hline & CC-II & -0.02 & 7.21 & 17.25 & 0.49 & 2.66 \\
\hline \multirow{5}{*}{$\mathbf{C}$} & LF-I & 0.34 & 10.37 & 19.64 & 0.36 & 2.39 \\
\hline & LF-II & 0.32 & 8.72 & 18.90 & 0.35 & 2.54 \\
\hline & LF-III & 0.06 & 9.91 & 18.61 & 0.56 & 2.54 \\
\hline & CC-I & 0.17 & 6.78 & 15.86 & 0.38 & 2.43 \\
\hline & CC-II & 0.16 & 6.08 & 15.30 & 0.61 & 2.36 \\
\hline \multirow{5}{*}{ D } & LF-I & 0.67 & 8.78 & 15.21 & 0.54 & 2.40 \\
\hline & LF-II & - & - & - & - & - \\
\hline & LF-III & 0.40 & 4.91 & 10.72 & 0.14 & 2.40 \\
\hline & CC-I & 0.35 & 5.99 & 13.28 & 0.55 & 2.36 \\
\hline & CC-II & 0.02 & 7.49 & 15.95 & 1.01 & 2.42 \\
\hline
\end{tabular}

The values of the shape parameter $\mathrm{k}$ are plotted in Figure 9. In almost all the fitted distributions, the $\mathrm{k}$ value was positive; therefore, the upper tail of each large inclusion distribution decayed to infinity. Furthermore, the k values are greater in the LF samples than in the CC samples, which means that there was a higher probability of finding large inclusions in the LF samples. This behavior is shown for Heat $\mathrm{C}$ in Figure 10, which shows the probability density function obtained from the calculated GEV model. It was observed that as the process went forward, the probability density function shifted to smaller inclusion sizes. 


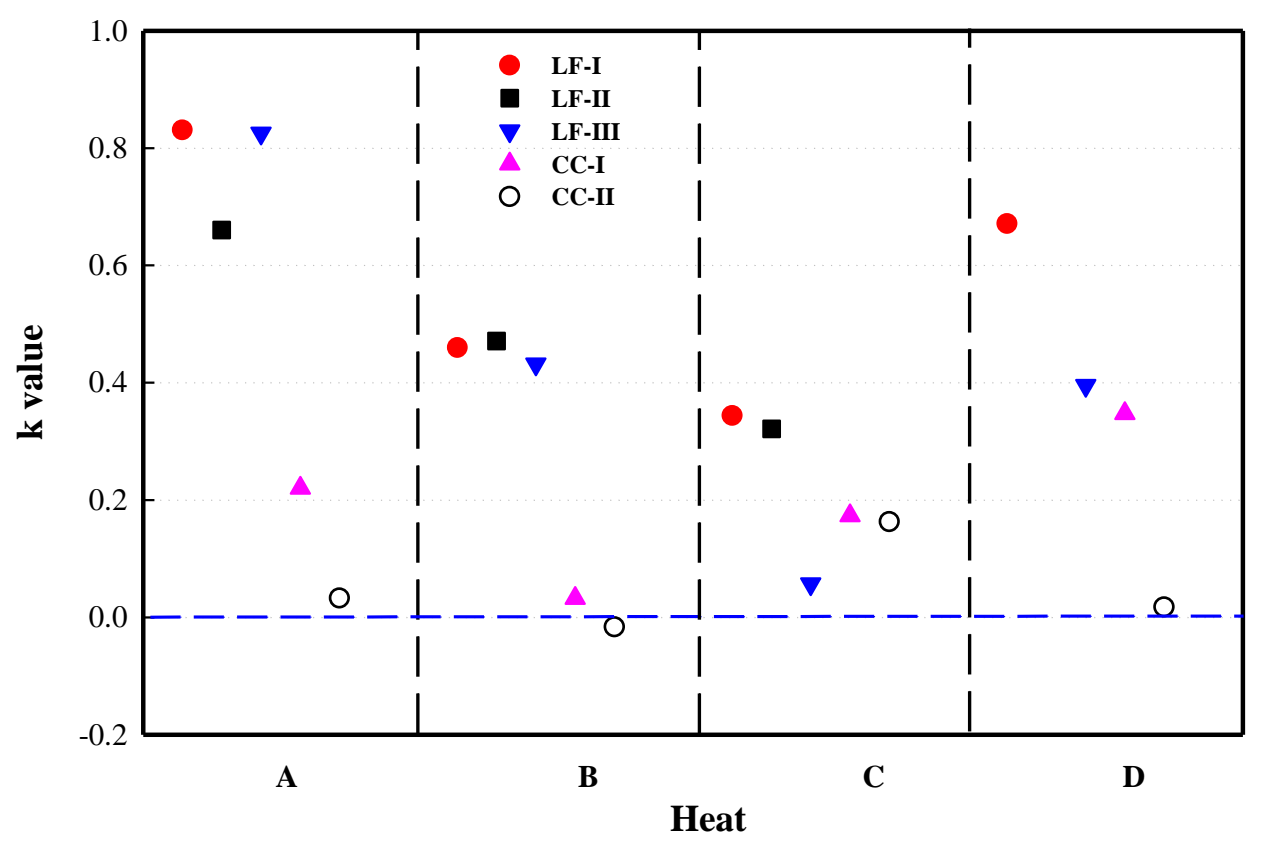

Figure 9. Values of the shape parameter k of the GEV distribution.

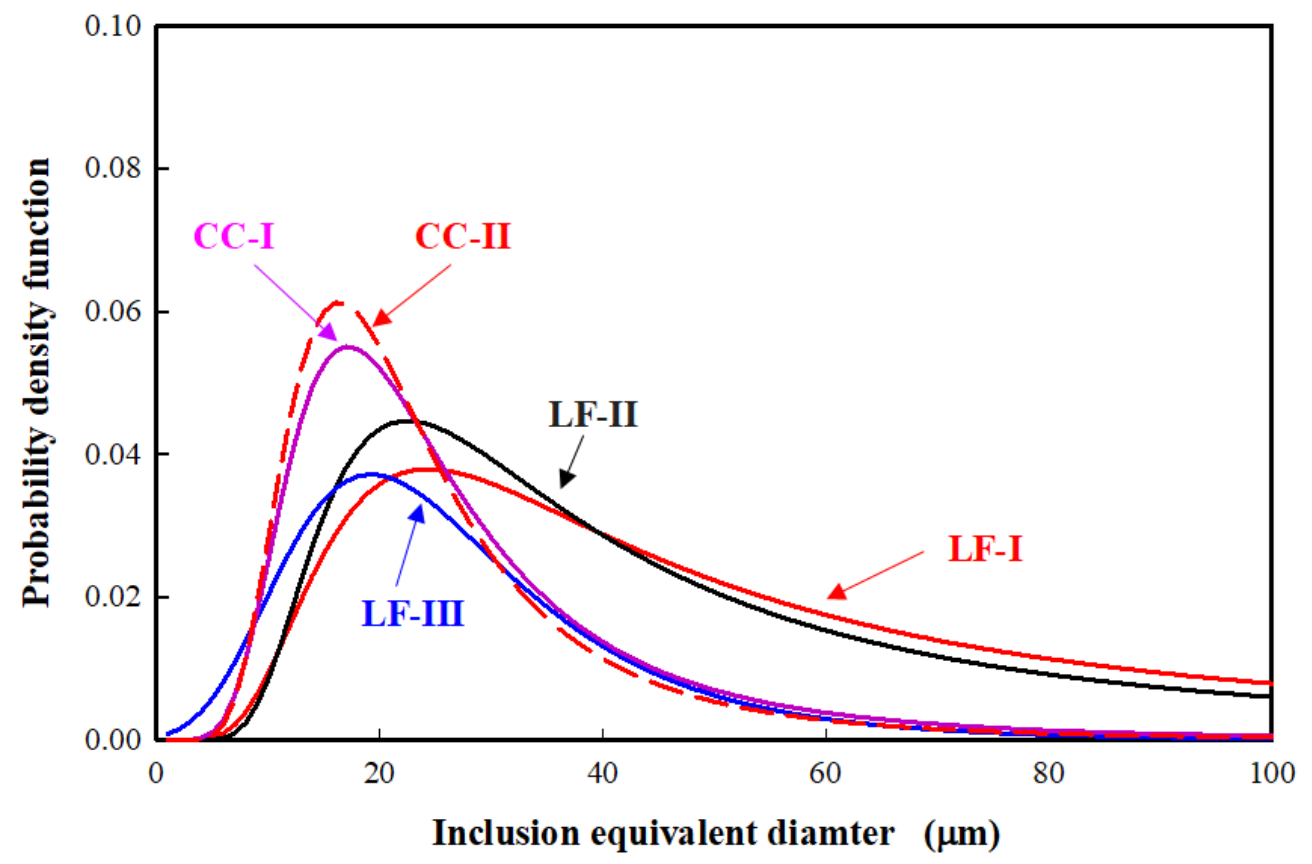

Figure 10. Evolution of the probability distribution function PDF for Heat C 
The comparison among heats of the probability density functions of the last three liquid steel samples, LF-III, CC-I and CC-II, is shown in Figure 11.

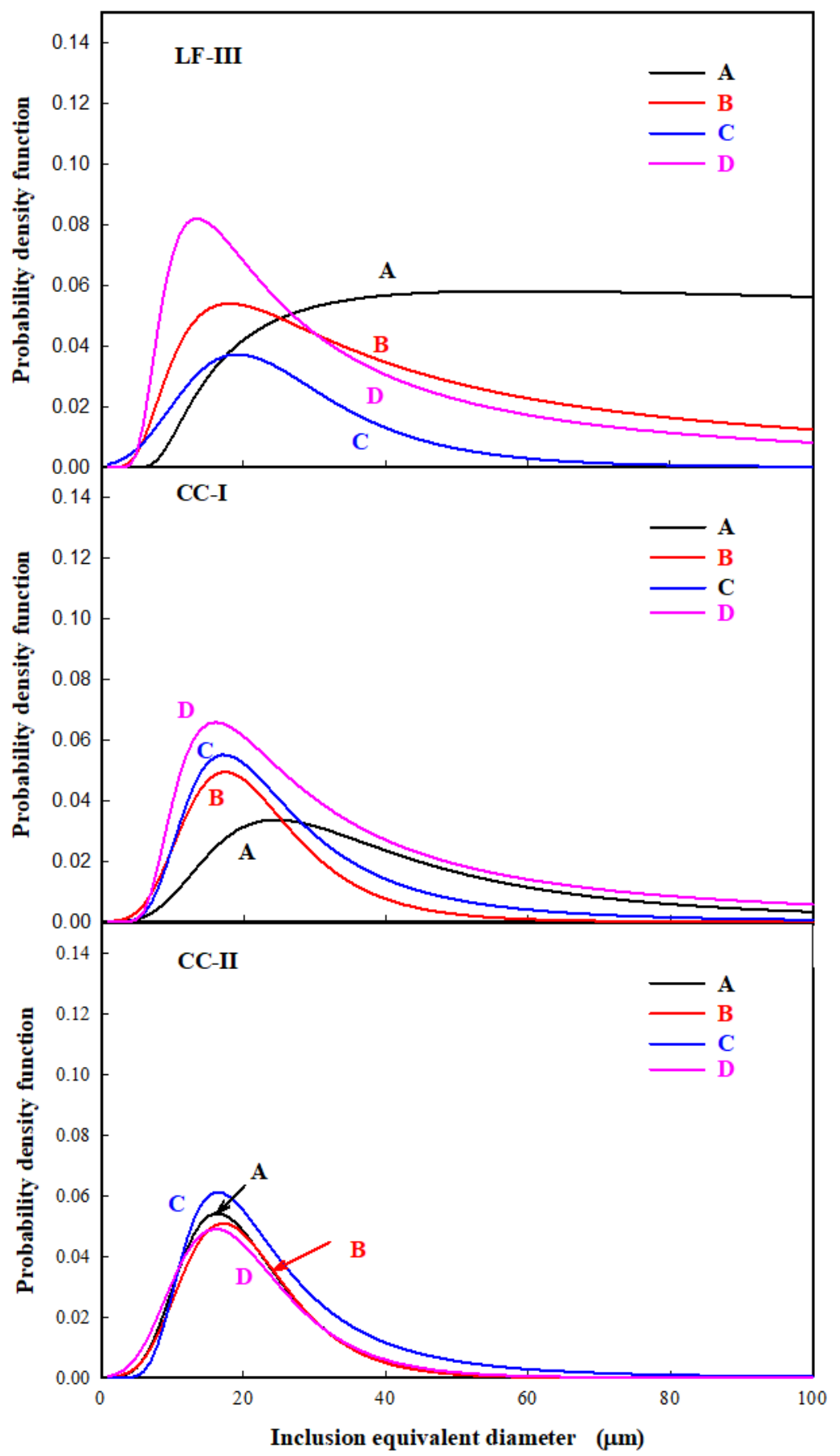

Figure 11. PDFs for CC samples. 
$14 / 05 / 2021$

It is worth noting that there were great differences among the probability density functions at the LF-III stage, particularly the locations and shapes of the upper tails, and these differences decreased progressively in the C-I and C-II samples. This result indicated that inclusion populations tended to resemble each other as the process progressed because large inclusions were removed in subsequent operations after $\mathrm{Ca}$ addition, as described previously in the section on PDFs.

The survival function $\mathrm{S}(\mathrm{x})$ was used to analyze the evolution of the inclusion populations. Figure 12 shows the variation in $\mathrm{S}(\mathrm{x})$ throughout the steel sampling sequence for the heats and three "critical" inclusion sizes: 20, 40 and $60 \mu \mathrm{m}$. These values were chosen based on the location of the PDFs shown in Figure 11.b and 11.c. corresponding to the CC samples, whose inclusion populations were expected to be like those in the solidified product.

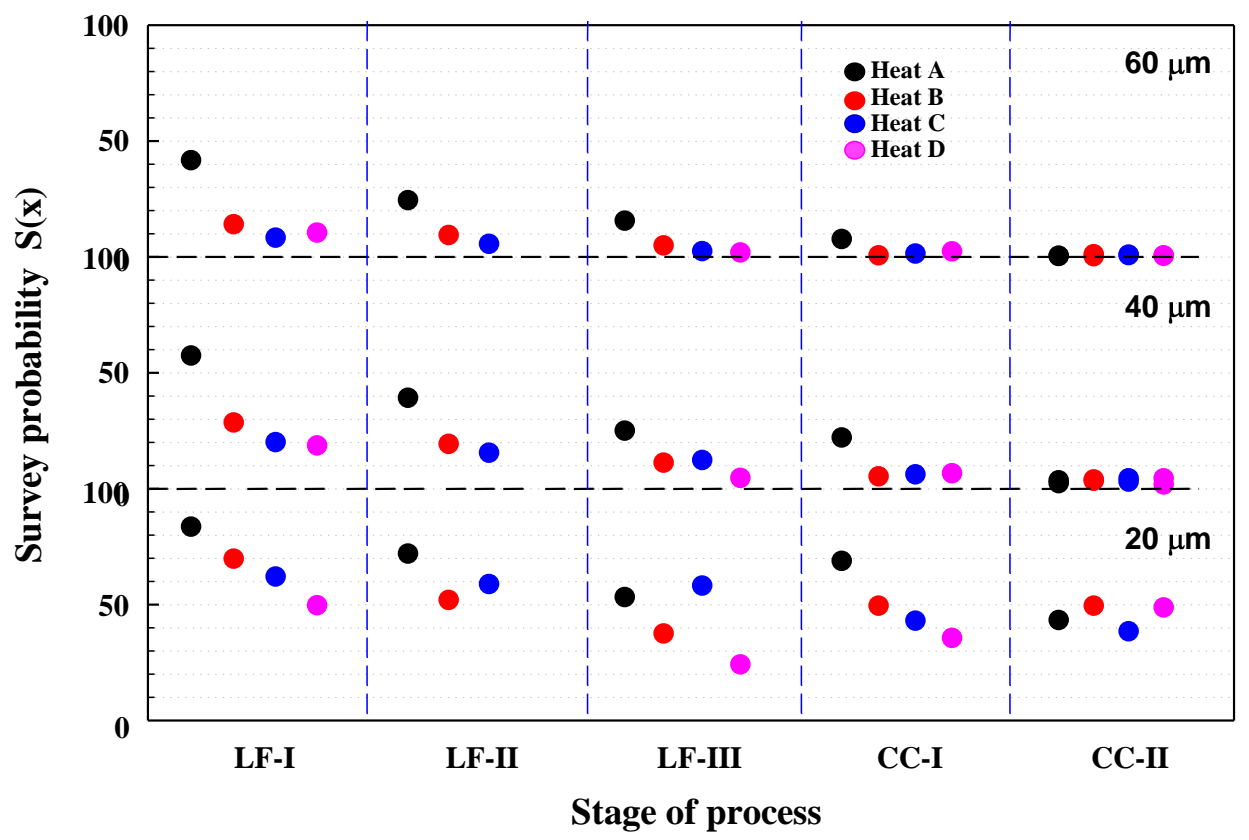

Figure 12. Evolution of the survival probability of inclusions for different "critical" sizes.

In general terms, the $\mathrm{S}(\mathrm{x})$ values decreased throughout the process regardless of the critical value of the inclusion size, and that behavior was more pronounced in the LF stages than that observed in the $\mathrm{CC}$ stages. This indicates that the removal of inclusions is greater during the treatment of liquid steel in the LF. Furthermore, the $\mathrm{S}(\mathrm{x})$ values decreased as the critical inclusion size increased, and its variation throughout the process decreased, 
indicating that the population of large inclusions decreased progressively. Additionally, the heats exhibited similar $\mathrm{S}(\mathrm{x})$ values at the CC-II sample and lower values than those of two previous stages, the LF-III and CC-I samples. This result suggested that after a certain amount of steel was cast, the inclusion populations became similar. Additionally, Heat A presented higher $\mathrm{S}(\mathrm{x})$ values throughout the process regardless of the critical inclusion size, which implied an increased probability of finding large inclusions in that heat.

Considering that Heat A showed a different behavior with respect to the rest of the heats, and it was excluded from the estimation of the average values of the CDFs throughout the process (Figure 13). It was observed that inclusions greater than $60 \mu \mathrm{m}$ are practically nonexistent in the CC-II samples. In contrast, the inclusion population between 40 and 60 $\mu \mathrm{m}$ was observed in all stages of the process and decreased as the process progressed. It is worth noting that this inclusion population still decreased between the LF-III and CC-I stages. In addition, it is observed that the population of inclusions less than $20 \mu \mathrm{m}$ is dominant in all stages of the process.

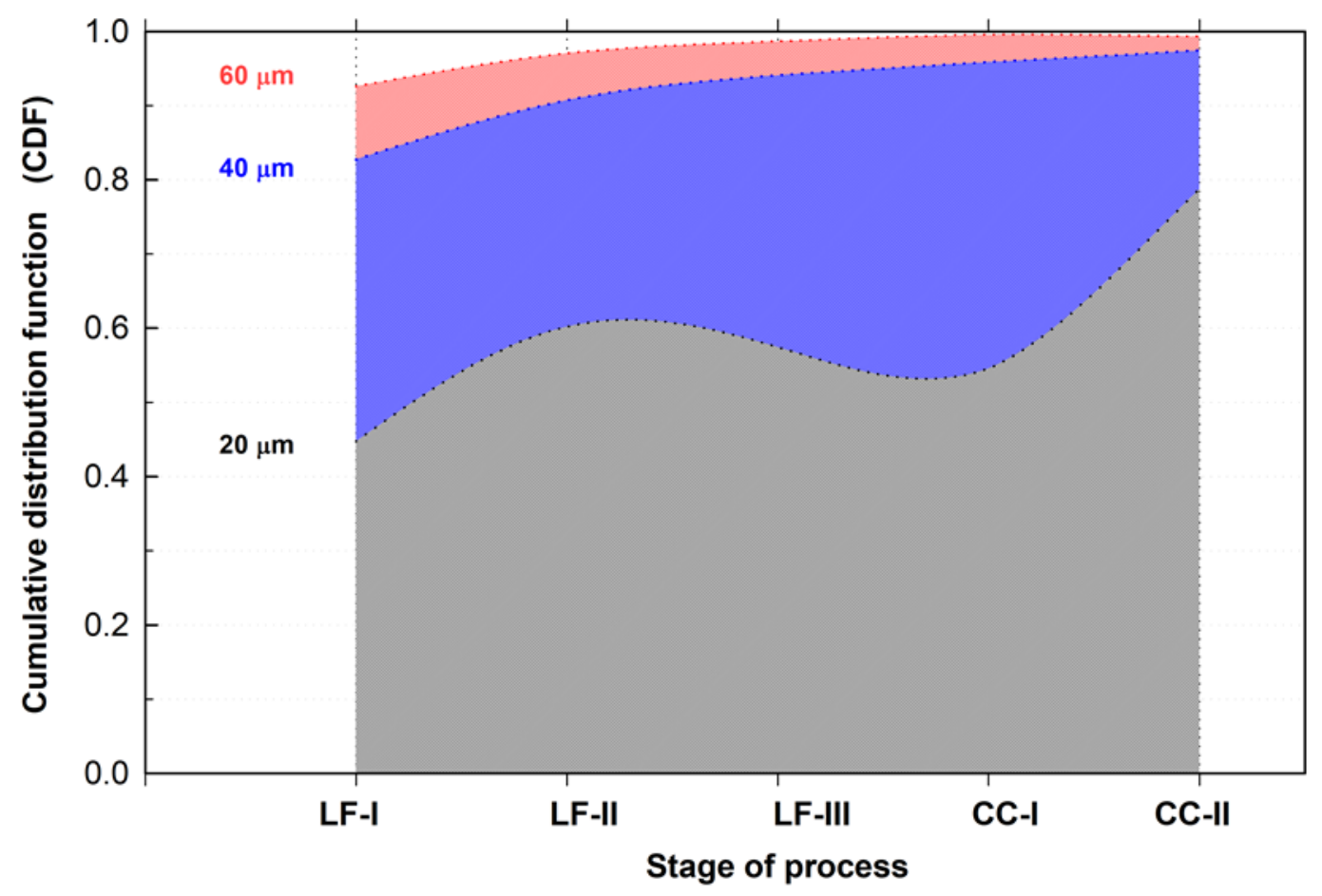

Figure 13. Evolution of the cumulative distribution function CDF for different "critical sizes". 
$14 / 05 / 2021$

The results showed that inclusion populations evolved significantly during the LF treatment regardless of the inclusion size and that differences were observed between the LFIII and CC samples. Figure 13 shows that during the LF treatment, initial large inclusions and large inclusions that resulted from the growth of small inclusions were removed. The size of the initial inclusions, $\mathrm{Al}_{2} \mathrm{O}_{3}$ and $\mathrm{Al}_{2} \mathrm{O}_{3}-\mathrm{MgO}$, varied over a wide range due to the different levels of saturation of $\mathrm{Al}$ and $\mathrm{O}$, which were promoted by the highly transient deoxidizing process. Furthermore, the initial inclusions became partly liquid during LF treatment because of the presence of $\mathrm{CaO}$ in the LF-II samples, as shown in Figure 3, and fully liquid after $\mathrm{Ca}$ addition, which promoted both the removal of inclusions and the growth of inclusions by collisions and hence, their flotation. The comparison among heats of the evolution of inclusion populations in the LF treatment showed that Heat A exhibited a greater number of larger inclusions in all LF stages and that behavior extended to the CC-I sample and was similar to behavior in the other heats up to stage CC-II. This result suggested that the inclusion population resulting from the deoxidation process plays a determinant role in the features of the inclusion population found in the $\mathrm{CC}$ samples. In this context, it is essential to control the amount and size of inclusions in the deoxidation process, particularly inclusions that become large during the process (assuming that the initial large inclusions are removed). The evolution of the inclusion populations between the LF-III and CC samples was associated with the residence time of the steel in the ladle, from $\mathrm{Ca}$ addition until the end of the $\mathrm{CC}$, as explained in the PDF section.

\section{Conclusions}

In this paper, the evolution of the chemical composition and size distribution of inclusions in samples obtained throughout a plant-scale slab production process was followed. Two approaches were used to analyze the size distributions: (1) estimation of PDFs following the Higgins formalism [18] to obtain information on the behavior of the global inclusion population, and (2) GEV theory to describe the upper tail of each size distribution. Thus, the following conclusions can be drawn.

- Solid $\mathrm{Al}_{2} \mathrm{O}_{3}$ and $\mathrm{Al}_{2} \mathrm{O}_{3}-\mathrm{MgO}$ inclusions formed by the deoxidation process were modified by $\mathrm{Ca}$ to form partly-liquid low- $\mathrm{CaO} \mathrm{Al}_{2} \mathrm{O}_{3}-\mathrm{MgO}-\mathrm{CaO}$ inclusions. This modification was associated with the steel-slag interactions during the LF treatment, 
which provided dissolved $\mathrm{Ca}$. This result agrees with that reported in the literature, which states that such types of inclusions are modified even at low Ca contents.

- Inclusions of $\mathrm{Al}_{2} \mathrm{O}_{3}-\mathrm{MgO}-\mathrm{CaO}$ with low $\mathrm{CaO}$ content were modified into fully liquid inclusions with an $\mathrm{Al}_{2} \mathrm{O}_{3} / \mathrm{CaO}$ ratio of approximately 1.25 and $\mathrm{MgO}$ contents lower than $10 \%$ through a $\mathrm{CaFeAl}$ wire treatment.

- The PDF approach allowed us to follow the evolution of inclusion size distributions throughout the process. Great changes in LF treatment and between the end of the LF treatment and the start of the CC process were observed. The PDF analysis revealed that new inclusions were not formed during the LF treatment; hence, the observed changes were associated with the growth and removal of inclusions. Furthermore, size distributions were similar at the end of the LF treatment regardless of their initial features. Differences among size distributions during the CC process were associated with variations in the residence time of inclusions in the liquid steel from the $\mathrm{Ca}$ addition to the progressive CC.

- The use of the GEV approach led to determining the form of the upper tails of the distributions, which in turn allowed us to follow their evolution and make a reliable comparison of the size distributions. Thus, the analysis of the shape parameter showed that the upper tail of each large inclusion distribution decayed to infinity. Regarding the evolution of the large inclusion distributions, they shifted to smaller sizes as the process advanced, and the changes were more appreciable in the LF treatment than in the $\mathrm{CC}$ process. Furthermore, great differences between the end of the LF treatment and the start of the progressive $\mathrm{CC}$ process were observed, and they were more apparent as the CC process advanced. This highlighted the importance of the increased residence time of inclusions in the liquid steel from the Ca addition to the progress of the $\mathrm{CC}$ operation. On the other hand, the probability of finding an inclusion larger than a given "critical" inclusion size and the cumulative distribution function were estimated, which was used to analyze their evolution throughout the steelmaking process for each of the studied heats as well as the comparison among distributions of different heats. 
$14 / 05 / 2021$

\section{References}

(1) Kaushik, P.; Lehmann, J.; Nadif, M. State of the Art in Control of Inclusions, Their Characterization, and Future Requirements. Metall. Mater. Trans. B 2012, 43 (4), 710-725.

(2) Pretorius, E. B.; Oltmann, H. G.; Schart, B. T. An Overview of Steel Cleanliness from an Industry Perspective. In AISTech Proceedings; 2013; pp 6-9.

(3) O’Malley, R. J. Inclusion Evolution and Removal in Ladle Refining. In AISTech 2017 conference and exposition, Nashville, TN; 2017; pp 8-11.

(4) Silva, A. D. C. E. Non-Metallic Inclusions in Steels-Origin and Control. J Mater Res Technol 2018, 7 (3), 283-299.

(5) Webler, B. A.; Pistorius, P. C. A Review of Steel Processing Considerations for Oxide Cleanliness. Metall. Mater. Trans. B 2020, 51 (6), 2437-2452.

(6) Liu, C.; Kumar, D.; Webler, B. A.; Pistorius, P. C. Calcium Modification of Inclusions via Slag/Metal Reactions. Metall. Mater. Trans. B 2020, 51 (2), 529-542.

(7) Liu, C.; Gao, X.; Ueda, S.; Guo, M.; Kitamura, S. Composition Changes of Inclusions by Reaction with Slag and Refractory: A Review. Isij Int. 2020, ISIJINT-2019.

(8) Shin, J. H.; Park, J. H. Prediction of Inclusion Evolution During Refining and Solidification of Steel: Computational Simulation and Experimental Confirmation. Metall. Mater. Trans. B 2020, 1-14.

(9) Kumar, D.; Pistorius, P. C. A Study on Calcium Transfer from Slag to Steel and Its Effect on Modification of Alumina and Spinel Inclusions. In Advances in Molten Slags, Fluxes, and Salts: Proceedings of the 10th International Conference on Molten Slags, Fluxes and Salts 2016; Springer, 2016; pp 145-153.

(10) Pretorius, E. B.; OLTMANN, H. G.; CASH, T. The Effective Modification of Spinel Inclusions by $\mathrm{Ca}$ Treatment in LCAK Steel. Iron Steel Technol. 2010, 7 (7), 31-44.

(11) Abraham, S.; Bodnar, R.; Raines, J.; Wang, Y. Inclusion Engineering and Metallurgy of Calcium Treatment. J. Iron Steel Res. Int. 2018, 25 (2), 133-145.

(12) Kim, J.-I.; Kim, S.-J. Evolution of Mg-Al-Based Inclusions with Changes in Mg Content during Ladle Treatment Based on a Coupled Reaction Model. ISIJ Int. 2020, 60 (4), 691-698.

(13) Tabatabaei, Y.; Coley, K. S.; Irons, G. A.; Sun, S. Model of Inclusion Evolution during Calcium Treatment in the Ladle Furnace. Metall. Mater. Trans. B 2018, 49 (4), 20222037.

(14) Tabatabaei, Y.; Coley, K. S.; Irons, G. A.; Sun, S. A Kinetic Model for Modification of MgAl 2 O 4 Spinel Inclusions During Calcium Treatment in the Ladle Furnace. Metall. Mater. Trans. B 2018, 49 (5), 2744-2756. 
$14 / 05 / 2021$

(15) Castro-Cedeno, E.-I.; Jardy, A.; Carre, A.; Gerardin, S.; Bellot, J. P. Thermal Modeling of the Injection of Standard and Thermally Insulated Cored Wire. Metall. Mater. Trans. B 2017, 48 (6), 3316-3328.

(16) Atkinson, H. V.; Shi, G. Characterization of Inclusions in Clean Steels: A Review Including the Statistics of Extremes Methods. Prog. Mater. Sci. 2003, 48 (5), 457-520.

(17) Van Ende, M.-A.; Guo, M.; Zinngrebe, E.; Blanpain, B.; Jung, I.-H. Evolution of Non-Metallic Inclusions in Secondary Steelmaking: Learning from Inclusion Size Distributions. ISIJ Int. 2013, 53 (11), 1974-1982.

(18) Higgins, M. D. Measurement of Crystal Size Distributions. Am. Mineral. 2000, 85 (9), 1105-1116.

(19) Murakami, Y. Inclusion Rating by Statistics of Extreme Values and Its Application to Fatigue Strength Prediction and Quality Control of Materials. Int. J. Fatigue 1996, 3 (18), 215.

(20) Ekengren, J.; Bergström, J. Extreme Value Distributions of Inclusions in Six Steels. Extremes 2012, 15 (2), 257-265.

(21) Castro-Cedeño, E.-I.; Herrera-Trejo, M.; Castro-Román, M.; Castro-Uresti, F.; López-Cornejo, M. Evaluation of Steel Cleanliness in a Steel Deoxidized Using Al. Metall. Mater. Trans. B 2016, 47 (3), 1613-1625.

(22) García-Carbajal, A.; Herrera-Trejo, M.; Castro-Cedeño, E.-I.; Castro-Román, M.; Martinez-Enriquez, A.-I. Characterization of Inclusion Populations in Mn-Si Deoxidized Steel. Metall. Mater. Trans. B 2017, 48 (6), 3364-3379.

(23) ASTM E2283-08. Extreme Value Analysis of Nonmetallic Inclusions in Steel and Other Microstructural Features, ASTM International, 2014.

(24) Bindeman, I. N. Fragmentation Phenomena in Populations of Magmatic Crystals. Am. Mineral. 2005, 90 (11-12), 1801-1815.

(25) Andersson, J.-O.; Helander, T.; Höglund, L.; Shi, P.; Sundman, B. Thermo-Calc \& DICTRA, Computational Tools for Materials Science. Calphad 2002, 26 (2), 273-312.

(26) Kang, Y.; Li, F.; Morita, K.; Sichen, D. Mechanism Study on the Formation of Liquid Calcium Aluminate Inclusion from MgO-Al2O3 Spinel. Steel Res. Int. 2006, 77 (11), 785792.

(27) Yang, S.; Li, J.; Gao, X.; Ma, Y. Modification Kinetics of MgO-A12O3 Inclusions by Ca-Treatment. Metall. Min. Ind. 2014, 2, 67.

(28) Verma, N.; Pistorius, P. C.; Fruehan, R. J.; Potter, M. S.; Oltmann, H. G.; Pretorius, E. B. Calcium Modification of Spinel Inclusions in Aluminum-Killed Steel: Reaction Steps. Metall. Mater. Trans. B 2012, 43 (4), 830-840.

(29) Holappa, L.; Hämäläinen, M.; Liukkonen, M.; Lind, M. Thermodynamic Examination of Inclusion Modification and Precipitation from Calcium Treatment to Solidified Steel. Ironmak. Steelmak. 2003, 30 (2), 111-115. 
(30) Gulbin, Y. On Estimation and Hypothesis Testing of the Grain Size Distribution by the Saltykov Method. Image Anal. Stereol. 2008, 27 (3), 163-174.

(31) Takahashi, J.; Suito, H. Evaluation of the Accuracy of the Three-Dimensional Size Distribution Estimated from the Schwartz-Saltykov Method. Metall. Mater. Trans. A 2003, 34 (1), 171-181.

(32) Van Ende, M.-A.; Guo, M. X.; Zinngrebe, E.; Dekkers, R.; Proost, J.; Blanpain, B.; Wollants, P. Morphology and Growth of Alumina Inclusions in Fe-Al Alloys at Low Oxygen Partial Pressure. Ironmak. Steelmak. 2009, 36 (3), 201-208.

(33) Zinngrebe, E.; Van Hoek, C.; Visser, H.; Westendorp, A.; Jung, I.-H. Inclusion Population Evolution in Ti-Alloyed Al-Killed Steel during Secondary Steelmaking Process. ISIJ Int. 2012, 52 (1), 52-61. 
Acknowledgments: M. Mata-Rodríguez and R. Sánchez-Martínez acknowledge the master science scholarship provided by the National Council of Science and Technology (CONACyT) for the realization of this work. M. Herrera-Trejo acknowledges Ternium for providing the facilities for the conduction of this work.

Author Contributions: M. Mata-Rodríguez and R. Sánchez-Martínez performed the experimental measurements and calculations and prepared the first draft; M. Herrera-Trejo analyzed the data and wrote the final manuscript; M. Castro-Román participated in the image analysis and data analysis in the context of the CONACyT Grant A1-S-44269; A. Martínez Enriquez participated in the data analysis and review of the manuscript; F. Castro-Uresti led the activities in plants and participated in the data analysis.

Conflicts of Interest: The authors declare no conflicts of interest. 